\title{
Comparison of Intravenous Gamma Globulin and a Monoclonal Anti-Fc Receptor Antibody as Inhibitors of Immune Clearance In Vivo in Mice
}

\author{
Roger J. Kurlander and Joan Hall \\ Division of Hematology-Oncology, Department of Medicine, Duke University Medical Center, Durham, North Carolina 27710
}

\begin{abstract}
Fc-receptor-mediated clearance and nonspecific phagocytic clearance were assessed after the infusion of monomeric human IgG, heat-aggregated human IgG, and a monoclonal anti-mouse macrophage FcII receptor antibody (2.4G2) into normal mice. Each agent blocked Fc-receptor function in vivo, but $2.4 \mathrm{G} 2$ was much more potent per microgram than the other agents. Monomeric IgG in blocking doses did not affect other aspects of immune function. In contrast, aggregated IgG, and to a lesser extent, 2.4G2 reduced serum complement levels. In addition, these agents also caused moderate reductions in nonspecific phagocytic function. Monoclonal anti-mouse macrophage C3bi receptor antibody (Mac-1), another monoclonal antibody which binds to macrophage $\mathrm{CR3}$ receptors without interfering with $\mathrm{Fc}$ receptor function, also reduced serum complement and inhibited nonspecific phagocytic function. Complement depletion alone (produced by infusion of cobra venom factor) could not account for the observed changes in Fc receptor or nonspecific phagocytic function. We conclude that both monomeric IgG and anti-Fcreceptor antibodies can markedly inhibit Fc-receptor function in vivo; however, the pattern of physiologic changes produced by these agents differs.
\end{abstract}

\section{Introduction}

In patients with autoimmune blood disorders, such as immune thrombocytopenia (ITP) ${ }^{1}$ and neonatal granulocytopenia, IgG Fc receptor-bearing leukocytes within the mononuclear phagocyte system (MPS) sequester and destroy blood cells coated with IgG autoantibodies. Normal monomeric human IgG (IGIV) prepared for intravenous infusion can suppress thrombocytopenia and granulocytopenia in these disorders (1-5). Though IGIV also may interact with platelets directly (6), it is well doc-

Received for publication 20 May 1985 and in revised form 2 February 1986.

1. Abbreviations used in this paper: CVF, cobra venom factor purified from Naje Haje; DHK, murine IgG2b monoclonal anti-dinitrophenyl/ trinitrophenyl antibody; EAs, mouse red cells coated with rabbit IgG anti-mouse red cell antibody; Es, autologous mouse red cells uncoated with antibody; HSA, human serum albumin; IGIV, monomeric human IgG; ITP, immune thrombocytopenia; Mac-1, monoclonal anti-mouse macrophage C3bi receptor antibody; MPS, mononuclear phagocyte system; SPA-Sepharose, staphylococcal protein A bound to Sepharose; TNBS, trinitrobenzene sulfonic acid; TNP, trinitrophenyl; TNP-EAs, TNP-coated mouse red cells incubated with IgG anti-trinitrophenyl antibody; TNP-Es, trinitrophenyl-coated mouse red cells; 2.4G2, monoclonal anti-mouse macrophage FcII receptor antibody.

\footnotetext{
J. Clin. Invest.

(C) The American Society for Clinical Investigation, Inc.

0021-9738/86/06/2010/09 \$1.00

Volume 77, June 1986, 2010-2018
}

umented that this agent can competitively inhibit Fc receptormediated clearance in vivo in man. Presumably the latter is a major mechanism by which IGIV reverses thrombocytopenia in adults with ITP.

Unfortunately, large amounts of IGIV $(2 \mathrm{~g} / \mathrm{kg})$ are required to therapeutically block immune destruction. Therefore, more efficient inhibitors of $\mathrm{Fc}$ receptor function might be clinically useful. Monoclonal antibodies specific for the binding site of IgG Fc receptors on macrophages $(7,8)$, neutrophils $(8,9)$, and natural killer cells $(9)$ have been identified based on their capacity to potently block the interaction of IgG-coated red cells with leukocytes in vitro. Since these can bind to Fc receptors with high avidity, they also might be potent inhibitors of the immune clearance of IgG-coated target cells in vivo. In fact, recent studies using a monoclonal anti-human $\mathrm{Fc}$ receptor antibody have demonstrated the capacity of a monoclonal antibody directed against a subpopulation of $\mathrm{Fc}$ receptors on human macrophages to reverse thrombocytopenia in patients with ITP (10).

In view of the potential clinical applications for these agents, the methodical assessment of their potency and specificity in an in vivo animal model for immune clearance seems warranted. To this end, we have studied the effects of IGIV and monoclonal anti-Fc receptor antibodies on MPS function in mice. A mouse model was chosen because prior studies have established that human, rabbit, and mouse IgG bind to Fc receptors on murine macrophages with similar avidity and specificity in vitro (11). Therefore, human IGIV also should block Fc receptor-mediated clearance of complexes containing rabbit or mouse IgG in vivo. In addition, the mouse is the only animal (other than man) for which well-defined monoclonal antibodies against macrophage Fc receptors $(2.4 \mathrm{G} 2$ ) and complement component $\mathrm{C} 3$ bi receptors (Mac-1) are both available $(7,12,13)$. Using a variety of assays for Fc receptor function adapted for or developed in this laboratory, we have assessed the effects of IGIV, IgG aggregates, 2.4G2, and Mac-1 on Fc receptor function and other aspects of MPS function in intact mice. Our results indicate that IGIV, heat aggregated IgG, and 2.4G2 each can markedly inhibit Fc receptor function in vivo, but these agents differ substantially in their potency and specificity.

\section{Methods}

Materials. Male C57/B16 $\times$ DBA/2 F1 mice (6-8 wk of age) were purchased from Jackson Laboratories (Bar Harbor, ME). Tissue culture supplies and Dulbecco's phosphate buffered saline (PBS) were obtained from Gibco (Grand Island, NY). ${ }^{125} \mathrm{I}$-sodium iodide and $\left[{ }^{51} \mathrm{Cr}\right]$ sodium chromate were purchased from Amersham Corp. (Arlington Heights, IL). Cobra venom factor purified from the venom of Naje Haje (CVF) was obtained commercially (Cordis Laboratories, Inc., Miami, FL).

The rat-mouse hybrid cell line producing $2.4 \mathrm{G} 2$ (7), a monoclonal antibody which binds specifically to the IgG1//gG2b Fc receptor on murine macrophages and lymphocytes (provided by Jay Unkeless, Rockefeller University, New York, NY), was grown intraperitoneally in nude mice and purified from the resultant ascites (14) by precipitation (using 
$50 \%$ saturated ammonium sulfate) followed by ion-exchange chromatography using DEAE-affigel blue (Bio-Rad Laboratories, Richmond, CA).

The rat-mouse hybrid cell line producing Mac-1 $(12,13)$, a monoclonal antibody which binds specifically to the CR3 (C3bi) receptor present on murine macrophages and neutrophils, was obtained from the American Type Culture Collection (Rockville, MD). Cells were grown in culture, and antibody was purified from the resultant tissue culture medium by ammonium sulfate precipitation and ion-exchange chromatography using DEAE-cellulose (12).

The murine hybrid cell line producing DHK, an IgG2b antibody which binds to dinitrophenyl and trinitrophenyl (TNP) groups was provided by Norman Klinman (Scripps Medical Institute, La Jolla, CA). Cells were injected intraperitoneally into pristane-primed CAF1 mice and murine IgG2b monoclonal anti-DNP/TNP antibody (DHK) was purified from the resultant ascites by affinity purification (15) using staphylococcal protein A bound to Sepharose (SPA-Sepharose) (Pharmacia Fine Chemicals, Piscataway, NJ) and an acetate buffer (pH 2.3).

Rabbit IgG anti-mouse red cell antibody was purified from a commercial anti-serum (Cooper Biomedical, Inc., Malvern, PA) by affinity purification using SPA-Sepharose. Rabbit anti-sheep red cell hemolysin antiserum was kindly provided by Dr. W. F. Rosse, Duke Medical Center, Durham, NC.

Purified IgG anti-human serum albumin (anti-HSA) was prepared from rabbit anti-HSA antiserum (Cooper Biomedical Inc., Malvern, PA) by affinity purification using columns containing HSA covalently bound to Sepharose 4B and SPA-Sepharose as described previously (14).

After purification, antibody preparations contained greater than $90 \%$ IgG as assessed by sodium dodecyl sulfate-polyacrylamide gel electrophoresis using reduced $12 \%$ or unreduced $5 \%$ polyacrylamide gels. Protein concentrations were determined using standard methods (16). The extent of aggregation of IgG preparations was assessed by gel filtration chromatography using Sepharose 4B (Pharmacia Fine Chemicals).

IGIV (Gamimune IV) was provided by Cutter Laboratories (Berkeley, CA) at a concentration of $50 \mathrm{mg} / \mathrm{ml}$. This preparation was prepared by ethanol precipitation of pooled human plasma from normal volunteers. Based on sodium dodecyl sulfate-polyacrylamide gel electrophoresis analysis, greater than $95 \%$ of the protein in this preparation is human IgG. To eliminate spontaneous aggregation, the product was equilibrated by the manufacturer in a low $\mathrm{pH}$ buffer ( $\mathrm{pH} 4.25$ ) containing $10 \%$ maltose, but the IgG in this preparation was not chemically modified in any other manner. The manufacturer has established that IGIV, in the doses used in these studies, does not significantly alter intravascular $\mathrm{pH}$ in animals.

Human IgG aggregates were prepared by heating IGIV, which had previously been dialyzed in PBS (pH 7.2) to remove maltose, at $63^{\circ} \mathrm{C}$ for $30 \mathrm{~min}$ (17). After heating, the preparation was turbescent, indicating the formation of colloidal aggregates of IgG. Aggregated IgG preparations routinely were stored at $4^{\circ} \mathrm{C}$ and used within $24 \mathrm{~h}$ after heat treatment.

Fc receptor-mediated clearance of antibody-coated red cells. To study the clearance of red cells coated with murine IgG, we assessed the rate of disappearance of autologous TNP-red cells (TNP-Es) coated with IgG2b DHK antibody (TNP-EAs). TNP-Es were prepared (18) from 40 $\mu \mathrm{l}$ of blood removed from the retroorbital complex of mice using a calibrated microcapillary tube (Accuppette Pipets, Dade Diagnostics, Aquada, Puerto Rico). After three washes with PBS, red cells were incubated with a $0.25-0.33 \mathrm{mg} / \mathrm{ml}$ solution of trinitrobenzene sulfonic acid (TNBS) dissolved in PBS (pH 7.0) for $30 \mathrm{~min}$ at room temperature. After excess TNBS was washed away, cells were washed once with $5 \mathrm{mM}$ glycylglycine and then three additional times with PBS. To radiolabel cells, TNP-Es were incubated with $10 \mu \mathrm{Ci}$ of sodium chromate containing ${ }^{51} \mathrm{Cr}$ (Amersham Corp., Arlington Heights, IL) for $30 \mathrm{~min}$ at $37^{\circ} \mathrm{C}$ and then washed three additional times. TNP-EAs were prepared by incubating these labeled cells for $30 \mathrm{~min}$ at room temperature with varying amounts of DHK (anti-TNP) just before infusion intravenously.

To study the clearance of EAs not bearing TNP groups on their surface, autologous Es were coated with rabbit anti-mouse red cell antibody. To this end, the packed red cells from $40 \mu$ l of blood were ${ }^{51} \mathrm{Cr}$ labeled as described above, and then incubated with $35 \mu \mathrm{g}$ of antibody in a total volume of $0.1 \mathrm{ml}$ for $30 \mathrm{~min}$ at $37^{\circ} \mathrm{C}$. Following incubation, cells were washed three times, resuspended in $0.3 \mathrm{ml}$ of PBS, and infused intravenously.

Following the infusion of radiolabeled TNP-Es, TNP-EAs, Es, or EAs into a lateral tail vein, $10 \mu \mathrm{l}$ samples of blood were removed from the retroorbital space $2,5,10,15,30,60,120,180$, and 240 min later. The percent red cells still in blood was calculated using a value for blood radioactivity at time 0 estimated by extrapolating from radioactivity at 2 and 5 min after red cell infusion, assuming first order kinetics for disappearance. Specific inhibition of Fc receptor-mediated clearance of TNP-EAs at $2 \mathrm{~h}$ after red cell infusion was calculated using the formula:

$\%$ inhibition of antibody-mediated red cell clearance

$$
=1-\frac{(\text { TNP-Es })-(\text { TNP-EAs })^{\text {exper }}}{(\text { TNP-Es })-(\text { TNP-EAs })^{\text {control }}},
$$

where TNP-Es represents the percent of TNP-coated cells left in blood $2 \mathrm{~h}$ after infusion in the absence of antibody; TNP-EAsexper represents TNP-EAs left in blood $2 \mathrm{~h}$ after infusion, in animals pretreated 90 min earlier with IGIV, heat-aggregated IgG, or monoclonal antibody; and TNP-EAs ${ }^{\text {control }}$ represents TNP-EAs in blood at $2 \mathrm{~h}$ in control animals pretreated with PBS in place of IGIV, IgG aggregates, or a monoclonal antibody.

In our experience, the rate of disappearance of Es was quite reproducible over time; however, the rate of disappearance of TNP-Es, TNPEAs, and EAs varied slightly with changes in the batch of TNBS or of antibody. Therefore, studies of the clearance of TNP-Es, TNP-EAs, and EAs in PBS-treated control animals (performed using the identical reagents during the same 1-2 wk period) always were performed in parallel with clearance studies in animals treated with putative MPS inhibitors.

To assess the sites of sequestration of Es and EAs, animals were killed $3 \mathrm{~h}$ after red cell infusion, and the amount of radioactivity within the blood, liver, spleen, lungs, heart, stomach, intestines, and kidneys measured directly using a gamma emission spectrometer. The total amount of radioactivity in the vascular space was calculated assuming the total blood pool equals $7 \%$ of body weight. The amount of radioactivity in each organ then was expressed as a percent of total counts recovered at the time of killing. Since only small amounts of radioactivity were present in non-MPS sites, for simplicity, only sequestration within the liver, spleen, lungs, and blood has been presented.

Fc receptor-mediated hepatic sequestration of HSA-anti-HSA immune complexes. This was quantitated using previously described methods $(14,19)$. In brief, purified IgG anti-albumin was radiolabeled with ${ }^{125}$ I (19), using Iodogen ( $1 \mu \mathrm{g}$ and $50 \mu \mathrm{Ci}$ of radioactive iodine per $10 \mu \mathrm{g}$ of protein). Radiolabeled HSA-anti-HSA complexes were prepared by mixing anti-HSA antiserum, trace-labeled with ${ }^{125}$ I labeled purified antiHSA ( $1 \mu \mathrm{g}$ of labeled antibody per $50 \mu \mathrm{l}$ of antiserum) with fivefold excess of HSA. Using gel filtration chromatography, we have previously shown that labeled anti-albumin in the absence of antigen migrates with the molecular weight of monomeric IgG, but after incubation with albumin, substantial amounts of immune complexes are formed (14). To measure clearance, radiolabeled HSA-anti-HSA complexes containing $2 \mu \mathrm{l}$ of anti-serum per gram body weight were infused intravenously. 90 min later, $10 \mu \mathrm{l}$ of packed autologous red cells (labeled with 200,000$400,000 \mathrm{cpm}$ of ${ }^{51} \mathrm{Cr}$ ) were infused and $10 \mathrm{~min}$ later (after equilibration of the red cells within the vascular space) duplicate $10-\mu l$ samples of blood were obtained and animals were killed by cervical dislocation. Radioactivity due to ${ }^{51} \mathrm{Cr}$ and ${ }^{125} \mathrm{I}$ within the visceral organs (as noted above) was measured using a two-channel gamma emission spectrometer. After radioactivity due to blood trapping was deducted from total radioactivity, the percent of total recoverable ${ }^{125}$ I-labeled complexes sequestered extravascularly in each organ at the time of killing was calculated (14). To assess the effects of inhibitors on Fc receptor-mediated hepatic sequestration of immune complexes, HSA-anti-HSA sequestration was assessed 90 min after the intraperitoneal infusion of each inhibitor or after the infusion of a comparable volume of PBS.

The percent inhibition of Fc receptor-mediated hepatic sequestration was calculated using the formula: 
\% inhibition of hepatic sequestration

$=1-\frac{(\text { HSA-anti-HSA })^{\text {experimental }}-(\text { anti-HSA })}{(\text { HSA-anti-HSA })^{\text {control }}-(\text { anti-HSA })}$,

where HSA-anti-HSA ${ }^{\text {experimental }}$ is the percent hepatic sequestration in animals receiving a putative MPS inhibitor prior to immune complexes; HSA-anti-HSA ${ }^{\text {control }}$ is the percent sequestration in animals pretreated only with PBS; and (anti-HSA) is the percent hepatic sequestration of labeled anti-HSA administered in the absence of antigen in animals pretreated with PBS. Prior studies have established that 2.4G2, a known inhibitor of immune complex clearance (14), even at high doses does not alter (anti-HSA) sequestration in the absence of antigen.

Heat-damaged red cells. Heat-damaged red cells were prepared (21) from thrice washed Es obtained from $\mathbf{4 0} \mu \mathrm{l}$ of heparinized blood obtained from the retroorbital space using calibrated pipets as described above. The cells, suspended in $1 \mathrm{ml}$ of PBS in a $12 \times 75 \mathrm{~mm}$ glass tube, were heated at $49.5^{\circ} \mathrm{C}$ for $10 \mathrm{~min}$ within a Lauda $\mathrm{K}-2$ thermostat adjusted to $49.5^{\circ} \mathrm{C}$, washed, and then labeled with ${ }^{51} \mathrm{Cr}$. The rate of disappearance of heated red cells from the circulation was monitored as described above.

Serum hemolytic complement. Serum hemolytic complement was measured by incubating twofold dilutions of serum $(50 \mu \mathrm{l})$ from treated or control animals with $30 \mu \mathrm{l}$ of a 1:5 dilution of a heat-treated $\left(56^{\circ} \mathrm{C}\right.$ for $10 \mathrm{~min}$ ) rabbit anti-sheep red cell hemolysin antiserum and $10 \mu \mathrm{l}$ of a $0.4 \%$ solution of thrice-washed sheep red cells. All reagents were diluted in a veronal-buffered saline containing $0.5 \mathrm{mM}$ calcium chloride and 1 $\mathrm{mM}$ magnesium chloride (22). The mixture was incubated at $37^{\circ} \mathrm{C}$ for $1 \mathrm{~h}$, at which time unlysed red cells were pelleted by centrifugation at $1,000 \mathrm{~g}$ for $10 \mathrm{~min}$, and the absorbance produced by released hemoglobin was quantitated spectrophometrically at $412 \mathrm{nM}$. Because of the lability of mouse complement, assays always were performed using freshly obtained serum. The CH50 titer was estimated from plots of $\log$ (serum concentration) versus $\log$ (fraction of red cells lysed)/(1 - fraction of red cells lysed) (22).

Complement depleted mice. Complement-depleted mice were prepared by injecting $2.5 \mathrm{U}$ of CVF in $0.5 \mathrm{ml}$ of PBS intraperitoneally at 12-h intervals for a total of four doses (23). Hemolytic complement assays and clearance studies were performed $18 \mathrm{~h}$ after the last dose of CVF. Hemolytic complement in animals treated in this manner was undetectable in our assay, representing at a minimum a 32-fold reduction in hemolytic complement levels compared to control mice.

Blood leukocyte concentrations. Blood leukocyte concentrations in treated animals were assessed serially after treatment with IGIV or monoclonal antibodies, using a hemocytometer. Microheriatocrits were determined using microcapillary tubes by standard clinical techniques.

Statistics. Confidence limits in all instances represent the standard deviation of the mean. The significance of differences between results in varying groups were assessed using the standard two-tailed $t$ test for unpaired samples.

\section{Results}

The extent of aggregation in the IgG preparations used to treat animals in these studies was assessed by gel filtration chromatography using Sepharose 4B (Fig. 1). IGIV and Mac-1 migrated as a single peak of monomeric IgG. The monoclonal anti-Fc receptor antibody $2.4 \mathrm{G} 2$ also was predominantly monomeric (97\%), although small amounts of aggregates could be detected. As expected, heat-treated IgG contained a heterogeneous mixture of aggregates and residual monomers.

Consistent with the reported tendency of heavily TNP-coated red cells to be ingested by macrophages (24), radiolabeled TNPEs infused into mice in the absence of antibody were cleared more rapidly than unmodified Es. However, at the level of TNP coating employed in these studies, more than half of the infused red cells remained in the blood for at least $4 \mathrm{~h}$. When TNP-Es

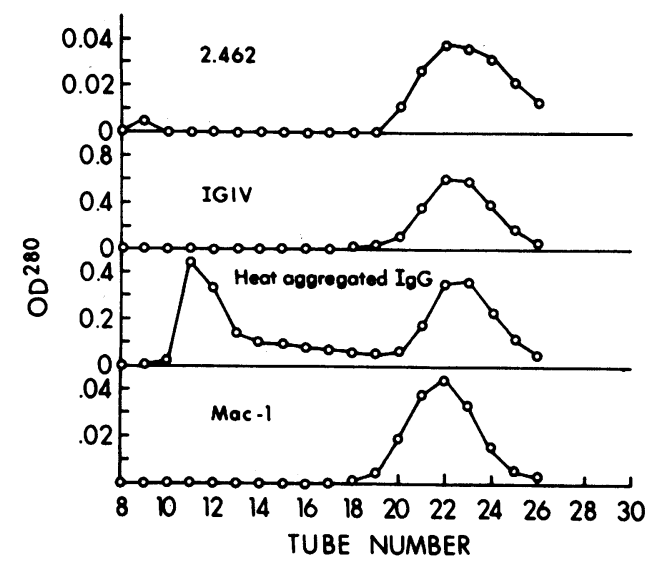

Figure 1. Comparison of the pattern of elution from Sepharose 4B of the IgG MPS blockers. $100 \mu$ l of each preparation was passed through a $1 \times 30-\mathrm{cm}$ column of gel, and the absorbance at $280 \mathrm{~nm}$ was monitored in each $0.7-\mathrm{ml}$ fraction.

were sensitized with increasing amounts of DHK to form TNPEAs, the rate of disappearance accelerated in a dose-dependent manner (Fig. 2). The acceleration of clearance was antigen-dependent since even $64 \mu \mathrm{g}$ of DHK did not alter the rate of disappearance of Es uncoated with TNP (data not shown). An antibody dose of $40 \mu \mathrm{g}$ routinely was used to sensitize TNP-Es for subsequent studies.

Intraperitoneal infusions of as little as $4 \mu \mathrm{g}$ per gram body weight of 2.4G2 almost completely inhibited antibody-dependent clearance of TNP-EAs (Fig. 3). At either 16 or $8 \mu \mathrm{g} / \mathrm{g}$ doses of $2.4 \mathrm{G} 2$, EA clearance differed from that in control animals with $P<.001$. Monomeric IGIV also profoundly blocked antibodydependent clearance, albeit at 100-1,000-fold greater concentrations than 2.4G2 (Fig. 4). At doses of 1,000 or $2,000 \mu \mathrm{g} / \mathrm{g}$, heat-aggregated IgG inhibited EAs clearance with intermediate

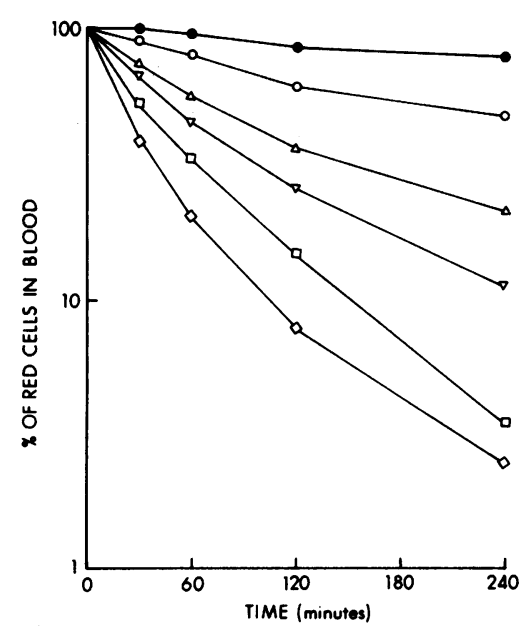

Figure 2. Comparison of the rate of disappearance of labeled TNP red cells after incubation in PBS alone (open circles) and after incubation with 8 (triangles), 16 (inverted triangles), 32 (squares), and 64 (diamonds) $\mu \mathrm{g}$ of DHK anti-TNP. The rate of disappearance of labeled red cells uncoated with TNP is illustrated with closed circles. Radiolabeled red cells were incubated in a final volume of $0.4 \mathrm{ml}$ either with PBS or with DHK antibody for $30 \mathrm{~min}$ at room temperature just prior to red cell infusion. Each point represents the mean value for two animals. 


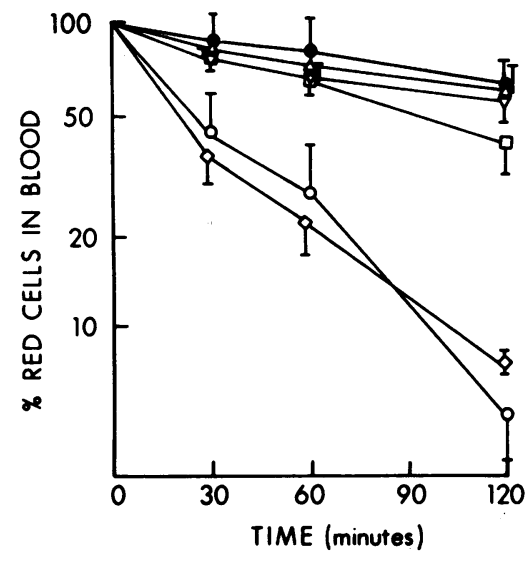

Figure 3. Comparison of the rate of disappearance of TNP-EAs (prepared using $40 \mu \mathrm{g}$ of DHK) in PBS-treated animals (open circles), and in animals pretreated with $2.4 \mathrm{G} 2$ at doses of 16 (triangles), 8 (inverted triangles), 4 (squares), and 2 (diamonds) $\mu \mathrm{g} / \mathrm{g}$ body weight given intraperitoneally $90 \mathrm{~min}$ prior to infusion. By comparison the rate of disappearance of TNP-Es is illustrated in closed circles. All points represent the mean for groups of three animals. The bars represent the standard deviations.

potency (Fig. 5). Mac-1, which interferes with the function of CR3 receptors (13), did not block clearance at doses of up to 40 $\mu \mathrm{g} / \mathrm{g}$ body weight (data not shown).

Though this model for immune hemolysis has the advantage of utilizing a murine antibody to mediate clearance, since at high levels TNP coating can induce ingestion of red cells by MPS cells even in the absence of antibody (24), the results obtained might not accurately reflect normal red cell immune clearance. Therefore, we also have studied the clearance of EAs. EAs disappear rapidly from the blood in normal mice. Although no single agent completely inhibited Fc receptor-mediated clearance of EAs, mice pretreated with $16 \mu \mathrm{g} / \mathrm{g}$ of $2.4 \mathrm{G} 2$, or $2,000 \mu \mathrm{g} / \mathrm{g}$ of IGIV, cleared these cells much more slowly than control animals $(P<0.001)$. Animals pretreated with Mac-1 cleared EAs as rapidly as controls (Fig. 6). These results are qualitatively quite similar to those obtained using TNP-EAs.

Since TNP-coated Es may be sequestered even in the absence of antibody, the effects of MPS blockers on the pattern of red cell sequestration was studied using Es and EAs exclusively. The pattern of sequestration of EAs in blood and the MPS is illustrated in Table I. $3 \mathrm{~h}$ after infusion into control mice, most EAs

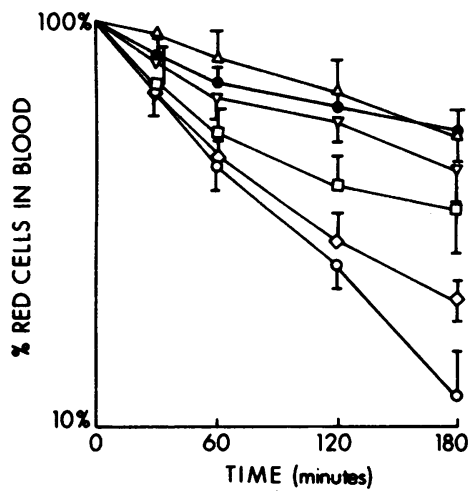

Figure 4. Comparison of the rate of disappearance of TNP-EAs in PBS-treated animals (open circles), and in animals pretreated with IGIV at doses of 2,000 (triangles), 1,000 (inverted triangles), 500 (squares), and 250 (diamonds) $\mu \mathrm{g} / \mathrm{g}$ body weight given i.p. $90 \mathrm{~min}$ prior to red cell infusion. By comparison the rate of disappearance (TNP-Es) is illustrated in closed circles. All points represent the mean for groups of three animals, and the bars represent the standard deviations.

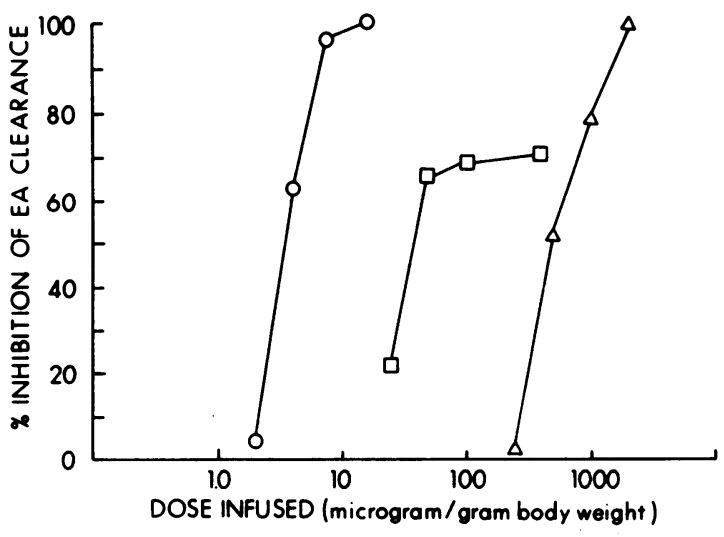

Figure 5. Comparison of the percent inhibition of Fc receptor-mediated clearance of TNP-EAs $2 \mathrm{~h}$ after infusion in animals previously treated with 2.4G2 (circles), IGIV (triangles), and IgG heat-aggregates (squares). Animals received varying doses of each agent $90 \mathrm{~min}$ before the infusion of red cells. Each point represents the mean for a group of at least three animals.

were sequestered in the liver and (to a more variable extent) in the spleen. Pretreatment with Mac-1 did not significantly alter this pattern of sequestration. Pretreatment with 2.4 G2 or IGIV, however, very significantly reduced sequestration within the liver, and increased the fraction of cells remaining within blood. Splenic sequestration, on the average, also was reduced by these agents, but this difference achieved statistical significance only in IGIV-treated animals.

We have demonstrated previously that $2.4 \mathrm{G} 2$ can block the clearance of soluble HSA-anti-HSA immune complexes (14). IGIV and heat-aggregated IgG also inhibited the clearance from blood and sequestration in the liver of HSA-anti-HSA complexes (Table II). As in studies of the clearance of EAs, 2.4G2 blocked the clearance of soluble HSA-anti-HSA immune complexes at much lower doses than IGIV or heat-aggregated IgG (Fig. 7).

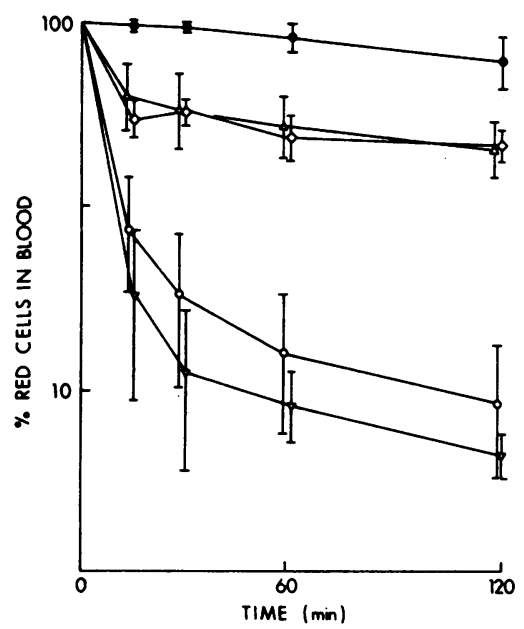

Figure 6. Comparison of the rate of disappearance of Es in animals pretreated with MPS blockers. Labeled EAs were infused into animals pretreated with PBS (open circles), 2.4G2 at $16 \mu \mathrm{g} / \mathrm{g}$ (diamonds), IGIV at $2,000 \mu \mathrm{g} / \mathrm{g}$ body weight (triangles), or Mac-1 at $40 \mu \mathrm{g} / \mathrm{g}$ (inverted triangles). The rate of clearance of Es in PBS-treated animals is illustrated in closed circles. Each group contains at least three animals. The bars represent the standard deviations. 
Table I. The Effect of MPS Inhibitors on the Pattern of Sequestration of Labeled Red Cells

\begin{tabular}{|c|c|c|c|c|c|}
\hline & & \multicolumn{4}{|c|}{ Percent of radioactivity sequestered within the MPS (mean \pm SD) } \\
\hline \multicolumn{2}{|l|}{ Animals receiving: } & Spleen & Liver & Lung & Blood \\
\hline & $n o . / 8 n$ & & & & \\
\hline \multirow[t]{2}{*}{$\mathrm{PBS}+\mathrm{ES}$} & $(3)^{*}$ & $1.2 \pm 0.1$ & $5.5 \pm 0.9$ & $4.5 \pm 0.3$ & $82.9 \pm 0.4$ \\
\hline & & $(P<0.01)$ & $(P<0.01)$ & & $(P<0.001)$ \\
\hline PBS + EAs & (4) & $21.7 \pm 7.6$ & $49.6 \pm 12.8$ & $4.6 \pm 0.7$ & $13.9 \pm 7.0$ \\
\hline \multirow[t]{2}{*}{$2.4 \mathrm{G} 2+$ EAs } & (2) & $12.1 \pm 2.2$ & $20.0 \pm 5.6$ & $5.1 \pm 1.2$ & $56.3 \pm 5.0$ \\
\hline & & & $(P<0.01) \ddagger$ & & $(P<0.01)$ \\
\hline \multirow[t]{2}{*}{ IGIV + EAs } & (4) & $8.7 \pm 4.9$ & $28.5 \pm 5.7$ & $6.2 \pm 2.7$ & $49.2 \pm 9.4$ \\
\hline & & $(P<0.05)$ & $(P<0.02)$ & & $(P<0.01)$ \\
\hline Mac-1 + EAs & (3) & $10.8 \pm 2.7$ & $63.7 \pm 8.7$ & $8.1 \pm 2.4$ & $9.4 \pm 2.2$ \\
\hline
\end{tabular}

* Animals were injected intraperitoneally with PBS, $16 \mu \mathrm{g} / \mathrm{g}$ of $2.4 \mathrm{G} 2,2,000 \mu \mathrm{g} / \mathrm{g}$ of IGIV, or $40 \mu \mathrm{g} / \mathrm{g}$ of Mac-1. 90 min later, animals received radiolabeled Es alone or EAs. $3 \mathrm{~h}$ later, the amount of radioactivity in the blood and internal organs was assessed as described in Methods. $\ddagger$ All $P$ values refer to the significance of difference compared to PBS-treated animals receiving EAs.

Consistent with findings above, Mac-1 did not interfere with the hepatic sequestration of immune complexes even at $40 \mu \mathrm{g} / \mathrm{g}$ body weight (data not shown).

To assess the specificity of MPS blockade, the effect of each agent on the clearance of heat-damaged Es was studied. Monomeric IGIV did not alter the rate of clearance of heat-damaged Es, but 2.4G2 and Mac-1 very significantly slowed their disappearance from blood. Heat-aggregated IgG also significantly reduced clearance compared to control animals, but this difference was less striking (Fig. 8 and Table III).

To assess the effects of inhibitors on complement levels in serum, blood hemolytic complement levels were compared before and $90 \mathrm{~min}$ after inhibitor infusions. IGIV did not reduce complement activity, but both monoclonal 2.4G2 and Mac-1 reduced complement levels substantially and heat-aggregated IgG depleted serum of complement (Table IV).

To assess the role of complement on EA clearance, the MPS function of animals depleted of complement by the infusion of CVF was assessed. CVF treatment substantially reduced the rate of EA disappearance (Fig. 9), confirming that complement played a significant role in clearance in this model. Mechanically, the reduced rate of red cell destruction following CVF treatment might result either from reduced fixation of the terminal complement components needed for the intravascular hemolysis of EAs, or from decrease fixation of $\mathrm{C} 3 \mathrm{~b}$, a component capable of enhancing the immune adherence of EAs to phagocytes within the MPS (25). When labeled Es and EAs were incubated with serum in vitro for $2 \mathrm{~h}$ at $37^{\circ} \mathrm{C}$, in each of two experiments there was less than $10 \%{ }^{51} \mathrm{Cr}$ release from Es, but $27 \%$ and $45 \%$ release from EAs. Thus, it is likely that the effect of CVF in part results from the blockade of complement-mediated intravascular hemolysis. In addition, since CVF treatment also reduced hepatic sequestration of EAs (Table V), it is likely that the latter mechanism also was important in vivo.

Since complement components play an important role in the elimination of EAs, the partial depletion of complement components observed following the infusion of $2.4 \mathrm{G} 2$ may contribute to its inhibitory effect on immune clearance. However, 2.4G2 clearly had a substantial independent effect on Fc receptor function even in CVF-treated animals without measurable hemolytic complement activity. In fact, though neither $2.4 \mathrm{G} 2$ nor CVF alone could completely block immune clearance, treatment with both agents caused a profound inhibition in the clearance of EAs from the blood (Fig. 9) and in the sequestration of EAs within the liver and spleen (Table V).

To assess whether complement depletion affected heat-damaged red cell clearance, the rates of disappearance were compared in control and CVF-treated animals. CVF-treated animals with $<3 \%$ of normal complement levels cleared heat-damaged red cells no more slowly than control animals (data not shown).

Table II. Comparison of the Pattern of Sequestration of Circulating Immune Complexes After Infusion of Inhibitors of Fc Receptor Function

\begin{tabular}{|c|c|c|c|c|c|c|}
\hline \multirow{2}{*}{$\begin{array}{l}\text { Radiolabeled } \\
\text { ligand: }\end{array}$} & \multirow[b]{2}{*}{ Pretreated with: } & \multirow{2}{*}{$\begin{array}{l}\text { No. of } \\
\text { animals }\end{array}$} & \multicolumn{4}{|c|}{ Percent of recoverable radioactivity within:* } \\
\hline & & & Spleen & Liver & Lung & Blood \\
\hline Anti-HSA & PBS & 6 & $0(0)$ & $6.4(0.5)$ & $1.0(0.1)$ & $82.0(1.2)$ \\
\hline HSA-anti-HSA & PBS & 3 & $0.7(0.3)$ & $37.3(2.1)$ & $0.8(0.3)$ & $46.0(3.4)$ \\
\hline HSA-anti-HSA & IGIV ( $2 \mathrm{mg} / \mathrm{g}$ ) & 3 & $0.2(0.2)$ & $24.1(1.5) \ddagger$ & $0.2(0.2)$ & $66.8(1.4) \ddagger$ \\
\hline HSA-anti-HSA & Aggregated IgG (2 mg/ml) & 3 & $0.1(0.1)$ & $14.2(7.4) \ddagger$ & $0.4(0.2)$ & $72.8(6.3) \ddagger$ \\
\hline
\end{tabular}

* Animals were pretreated intraperitoneally with PBS or IgG. 90 min later, labeled anti-HSA or HSA-anti-HSA were infused and the percent of radioactivity sequestered within the MPS quantitated. The results represent mean (SD) for each group. $¥$ Result differs from that of animals receiving HSA-anti-HSA after PBS with a $P<0.001$. 


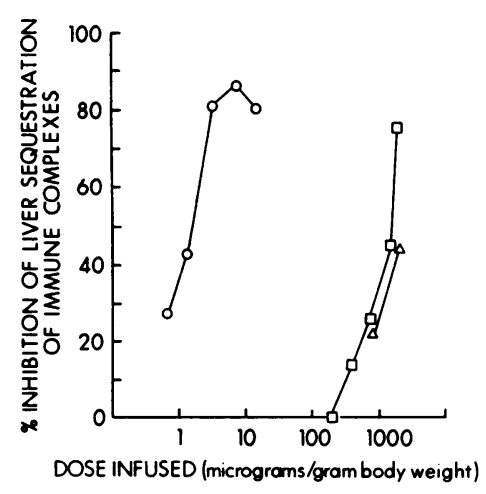

Thus, complement depletion alone cannot account for the MPS defect noted after monoclonal antibody infusion.

Though leukocytes bear antigens recognized by $2.4 \mathrm{G} 2$ and Mac-1, neither antibody, IGIV, nor heat-aggregated IgG depressed blood leukocyte concentrations. In fact, each agent modestly increased the leukocyte counts. None of the IgG preparations significantly altered microhematocrits (data not shown).

\section{Discussion}

Since binding to leukocyte Fc receptors is a prerequisite for the immune destruction of IgG-coated cells, soluble ligands, such as IgG monomer (26), IgG aggregates (27), and anti-Fc receptor antibodies (7-9), each can competitively inhibit antibody-dependent, leukocyte-mediated destruction of EAs in vitro. The goals of these studies were to compare the efficacy of IGIV and monoclonal anti-macrophage antibodies in blocking Fc receptor function in vivo, and to assess the effects of each agent on other aspects of MPS function. Our results indicate that anti-receptor antibodies are much more potent inhibitors of immune function in vivo than IGIV, but that this increase in potency is achieved at the expense of some loss in specificity of action.

To study the effects of IGIV and monoclonal antibodies on IgG antibody-coated target cell clearance, we measured clearance in vivo of TNP-Es coated with anti-TNP and of EAs. The antibody-dependent destruction of TNP-EAs could be almost completely inhibited using several Fc receptor blockers, suggesting that clearance was mediated predominantly by Fc receptor bearing leukocytes. Though Fc receptor blockade also inhibited EA disappearance, destruction of these cells could not

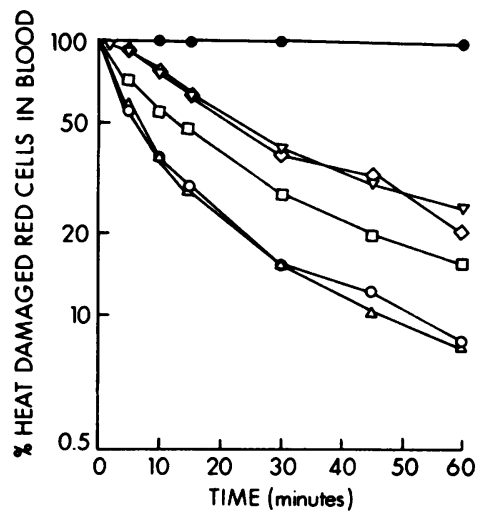

Figure 8. Comparison of the rate of disappearance of heat-damaged Es in mice 90 min after the infusion of 2.4G2 (diamonds), IGIV (triangles), IgG heat-aggregates (squares), Mac-1 (inverted triangles), and $\mathrm{PBS}$ alone (circles) at the same doses employed in Fig. 6. The rate of disappearance of unheated red cells is illustrated in closed circles. Each group represents at least three animals. be as completely inhibited using Fc receptor blockers alone. Since our EAs could fix sufficient complement to produce measurable complement-dependent lysis in vitro, and since complement depletion and Fc receptor blockade seemed to exert separate and additive inhibitory effects on EA destruction in vivo, we presume that the terminal components of complement also contributed to lysis in this model.

In prior guinea pig and human studies of Fc receptor-mediated clearance (utilizing EAs which did not fix complement extensively), cell sequestration occurred predominantly in the spleen $(25,28)$. In contrast, most EAs in the current studies were trapped within the liver. Since $\mathrm{C} 3 \mathrm{~b}$ coating is known to facilitate hepatic sequestration $(25,28)$, this difference in pattern of uptake may reflect the greater levels of complement components bound to our EAs compared to those used in prior studies. In addition, it is conceivable that species-related differences in MPS structure and function also may have played a role.

Complement components as well as IgG often are found on the surface of red cells from patients with immune hemolysis (28) and on platelets from patients with ITP (29). When present, such components commonly may play a significant role in facilitating MPS sequestration. Less commonly, IgG antibodies fix sufficient complement to cause clinically significant intravascular lysis (29). Obviously, the potential effectiveness of Fc receptor blockade alone as a strategy for inhibiting immune destruction diminishes as the role of complement in directly lysing cells increases. However, our studies using EAs illustrate that even when significant amounts of complement are bound to target cells, Fc receptor blockade still can reduce immune destruction substantially.

IGIV was an effective inhibitor of Fc receptor-mediated clearance of TNP-EAs, EAs, and immune complexes. Since there are significant species differences in the amino acid structure of IgG, not all species of heterologous IgG would be suitable as a blocking agent in a murine model. However, since prior studies have established that murine, rabbit, and human IgG each bind to IgG2a and IgG2b/IgG1 Fc receptors on murine leukocytes with comparable avidity in vitro (11), we felt it reasonable to use human IgG to competitively inhibit murine Fc receptor function in vivo. In fact, the dose of IGIV required to produce high grade inhibition of murine Fc receptor function $(2 \mathrm{mg} / \mathrm{g}$ body weight) was identical to that found empirically to reverse thrombocytopenia in patients with ITP (1-4), suggesting that IGIV has similar efficacy in mouse and man. Since IGIV already is in active use in blocking Fc receptor function in patients with autoimmune blood disorders, it was reassuring to observe that this agent appears to be a very selective inhibitor of MPS function. MPS clearance of heat-damaged red cells, blood leukocyte concentrations, and serum hemolytic complement activity were unaffected even by large IGIV infusions.

Human IgG aggregates block Fc receptor function in vitro more efficiently than IgG monomer, presumably as a result of the greater avidity with which multivalent complexes bind to Fc receptor-bearing cells $(30,31)$ and to the capacity of such complexes to downregulate Fc receptors (32). In vivo aggregates were comparable in potency or slightly more potent than monomeric IgG in blocking Fc receptor-mediated clearance. Unlike IGIV monomer, however, aggregated IgG profoundly depleted serum complement and also may have diminished the nonspecific MPS clearance of heat-damaged Es. The former presumably results from the activation of Clq by aggregated IgG (33), and the latter would be predicted based on prior demonstrations 
Table III. Comparison of Heat-damaged Red Blood Cell Clearance Before and After Treatment of Animals with IgG Preparations

\begin{tabular}{|c|c|c|c|c|}
\hline \multirow[b]{2}{*}{ Animals pretreated* with: } & \multirow{2}{*}{$\begin{array}{l}\text { Group } \\
\text { size }\end{array}$} & \multicolumn{3}{|c|}{ Percent of radioactivity in blood (minutes after red cell infusion) } \\
\hline & & 5 & 15 & 60 \\
\hline PBS & 15 & $54.8 \pm 21.0$ & $29.2 \pm 17.3$ & $9.3 \pm 4.5$ \\
\hline IGIV (2 mg/g) & 5 & $57.1 \pm 14.5$ & $28.1 \pm 15.5$ & $8.2 \pm 2.8$ \\
\hline Heat-aggregated IgG ( $2 \mathrm{mg} / \mathrm{g})$ & 6 & $\begin{array}{l}71.2 \pm 10.4 \\
(P<0.05) \ddagger\end{array}$ & $47.4 \pm 18.6$ & $15.5 \pm 11.8$ \\
\hline $2.4 \mathrm{G} 2(16 \mu \mathrm{g} / \mathrm{g})$ & 4 & $\begin{array}{l}92.0 \pm 7.7 \\
(P<0.001)\end{array}$ & $\begin{array}{l}60.9 \pm 5.9 \\
(P<0.001)\end{array}$ & $\begin{array}{l}19.6 \pm 5.3 \\
(P<0.01)\end{array}$ \\
\hline $\operatorname{Mac}-1(40 \mu \mathrm{g} / \mathrm{g})$ & 4 & $\begin{array}{l}89.3 \pm 9.6 \\
(P<0.001)\end{array}$ & $\begin{array}{l}60.9 \pm 3.6 \\
(P<0.001)\end{array}$ & $\begin{array}{l}24.0 \pm 0.7 \\
(P<0.001)\end{array}$ \\
\hline
\end{tabular}

* Animals received PBS or IgG preparations intraperitoneally followed 90 min later by the infusion of radiolabeled Es which had been heated to $49.5^{\circ} \mathrm{C}$ for $10 \mathrm{~min}$ as described in Methods. $¥ P$ values compared to blood levels in PBS-treated control animals.

of MPS blockade following the infusion of colloidal suspensions (34).

Since small amounts of aggregated IgG would be anticipated to form spontaneously in IGIV, aggregates of IgG, rather than IgG monomer itself, conceivably could be the component of IGIV responsible for MPS Fc receptor blockade (4). However, IgG aggregates constituted only a minor contaminant in IGIV preparations. Therefore, unless naturally occurring aggregates have much greater biologic activity than heat-aggregated IGIV, these could not account for the level of inhibition of Fc receptor function observed in our studies. The absence of complement depletion after IGIV infusion and (to a lesser extent) the absence of defects in MPS clearance of heat-treated red cells after IGIV infusion also suggest substantial quantities of aggregates are not formed in vivo. Segal, Dower, et al. (35) have developed a mathematical model for describing the equilibrium binding of multivalent IgG complexes to Fc receptor bearing cells. Such calculations imply that even though multivalent ligands bind to receptors much more efficiently than monomers, the infusion of exogenous monomeric IgG in vivo should competitively inhibit the binding of multivalent ligands (such as IgG coated cells and immune complexes) to MPS cells. Our data seem to provide empirical support for this conclusion. Nonetheless, we cannot rule out the possibility that small IgG complexes are formed in vivo which are capable of potently blocking Fc receptors without depleting complement.

Table IV. Effects of IgG Preparations on Hemolytic Complement Titers

\begin{tabular}{lllll}
\hline & \multicolumn{5}{c}{$\begin{array}{l}\text { Mean hemolytic } \\
\text { complement titer }\end{array}$} \\
\cline { 3 - 5 } Animals treated with: & $\begin{array}{l}\text { No. of } \\
\text { animals }\end{array}$ & Before (SD) & After (SD) \\
\hline & & & & $\%$ change* \\
$2.4 G 2$ & 4 & $101(13)$ & $43(13) \ddagger$ & $58 \%$ \\
IGIV & 3 & $69(5)$ & $64(4)$ & $7 \%$ \\
IgG heat aggregates & 3 & $45(3)$ & $\$$ & - \\
Mac-1 & 3 & $71(8)$ & $54(6)^{*}$ & $23 \%$ \\
& & & & \\
\hline
\end{tabular}

* Change significant with $P<0.05$.

¥ Change significant with $P<0.001$.

$\S$ Too low to measure.
We have previously demonstrated that $2.4 \mathrm{G} 2$ very potently inhibits MPS clearance of immune complexes (14). Indeed, 2.4G2 also blocked EA clearance with similar potency. This antibody also partially depleted serum hemolytic complement, presumably by fixing components to the surface of antibodycoated leukocytes. In view of this, $2.4 \mathrm{G} 2$ conceivably might decrease EA clearance not only by blocking Fc receptors but also by decreasing the amount of $\mathrm{C} 3$ or other complement components fixed to red cells. Clearly, the profound effect of $2.4 \mathrm{G} 2$ on immune clearance is not merely a consequence of complement depletion, since $2.4 \mathrm{G} 2$ still dramatically reduces $\mathrm{Fc}$ receptor function even in animals depleted of complement by prior treatment with CVF. In fact, our data (Fig. 9) dramatically illustrate the additive effect of complement depletion and Fc receptor blockade in preventing IgG mediated immune clearance.

Prior in vivo studies have demonstrated a role for $\mathrm{C} 3 \mathrm{~b}$ and possibly for $\mathrm{C} 3 \mathrm{bi}$ in the immune clearance of IgG-coated red cells (25). However, Mac-1, an antibody which blocks C3bi receptor function (13), did not alter the immune clearance of EAs in vivo. This suggests that, at least in the model system employed

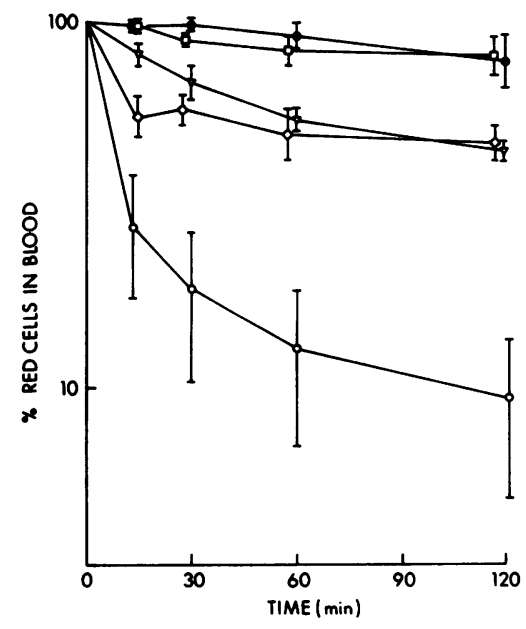

Figure 9. Comparison of the disappearance of EAs in control mice (open circles), in CVF-treated mice (inverted triangles), in 2.4G2 treated mice (open diamonds), and in mice receiving both agents (squares). For comparison, the disappearance of Es in PBS-treated animals is illustrated in closed circles. The bars represent the standard deviations. 


\begin{tabular}{|c|c|c|c|c|c|}
\hline \multirow[b]{2}{*}{ Animals receiving: } & & \multicolumn{4}{|c|}{ Percent of radioactivity sequestered within the MPS (mean \pm SD): from sites of sequestration* } \\
\hline & & Spleen & Liver & Lung & Blood \\
\hline & No. $p$ & & & & \\
\hline \multirow[t]{2}{*}{ PBS + Es } & (3) & $1.2 \pm 0.1$ & $5.5 \pm 0.9$ & $4.5 \pm 0.3$ & $82.9 \pm 0.4$ \\
\hline & & $(P<0.01)$ & $(P<0.01)$ & & $(P<0.001)$ \\
\hline PBS + EAs & (4) & $21.7 \pm 7.6$ & $49.6 \pm 12.8$ & $4.6 \pm 0.7$ & $13.9 \pm 7.0$ \\
\hline \multirow[t]{2}{*}{ CVF + EAs } & (3) & $23.7 \pm 2.5$ & $27.0 \pm 1.8$ & $1.3 \pm 0.2$ & $43.8 \pm 0.8$ \\
\hline & & & $(P<0.02) \ddagger$ & $(P<0.01)$ & $(P<0.01)$ \\
\hline \multirow[t]{2}{*}{$(\mathrm{CVF}+2.4 \mathrm{G} 2)+\mathrm{EAs}$} & (3) & $7.0 \pm 1.9$ & $7.8 \pm 1.6$ & $1.9 \pm 0.1$ & $77.8 \pm 4.3$ \\
\hline & & $(P<0.01)$ & $(P<0.01)$ & $(P<0.01)$ & $(P<0.01)$ \\
\hline
\end{tabular}

* Animals pretreated for $2 \mathrm{~d}$ with CVF (see Methods) or 90 min earlier with $2.4 \mathrm{G} 2$ (16 $\mu \mathrm{g} / \mathrm{g}$ body weight) received radiolabeled Es alone or EAs. $3 \mathrm{~h}$ later, the amount of radioactivity in the blood and internal organs was assessed as described in Methods. $¥$ All $P$ values refer to the significance of difference compared to comparable value in PBS-treated animals receiving EAs.

for these studies, interaction of $\mathrm{C} 3$ bi with leukocyte $\mathrm{CR} 3$ receptors is not very important in the clearance of IgG EAs.

Despite their immunochemical specificity, 2.4G2 and Mac1 also inhibited the nonspecific clearance of heat-damaged Es. Heat-damaged Es reportedly do not bear increased amounts of IgG (or complement) on their surface (21), and thus are presumed to be cleared by a combination of splenic trapping (due to their increased rigidity) and recognition as "damaged" cells by the MPS. Our studies provide further strong evidence that the clearance of these cells is not dependent either on Fc receptor or complement receptor function. Doses of IGIV which block Fc receptor function and of CVF which profoundly deplete hemolytic complement do not alter heat-damaged Es clearance. In view of this, $2.4 \mathrm{G} 2$ and Mac-1 presumably inhibit nonspecific MPS function either by altering MPS cell function by some other as yet unknown mechanism or by significantly altering the rate of blood flow through the liver and spleen.

A similar blockade of MPS phagocytic function can be produced by the infusion of colloids in vivo. Colloids block MPS function both by interfering with the phagocytic function of leukocytes and by depleting serum of opsonic factors, especially fibronectin (34). Anti-macrophage antibodies could inhibit MPS function by initiating complement-mediated destruction of macrophages, but this is unlikely for two reasons: $(a)$ mouse serum does not lyse 2.4G2- or Mac-1-coated murine cells (12), and $(b)$ 2.4G2 can nonspecifically inhibit MPS function even in C5 deficient animals (14). Conceivably the noncytotoxic binding of complement components to cells, or the depletion of serum opsonic factors may account for the inhibition noted in these studies. This mechanism of suppression requires further evaluation in view of the growing interest in the use of a variety of monoclonal anti-leukocyte antibodies as therapeutic agents.

Our results raise questions about the safety of Fc receptor blocking agents in some situations. Each of the agents tested (including IGIV) inhibits the clearance of immune complexes as well as IgG-coated target cells. MPS Fc receptor bearing cells are important in clearing some types of circulating agents in some situations. Each of the agents tested (including IGIV) inhibits the clearance of immune complexes as well as IgG-coated target cells. MPS Fc receptor bearing cells are important in clearing some types of circulating immune complexes, presumably preventing their deposition in peripheral tissues where they could cause tissue damage. Therefore the blockade of Fc receptor function produced by large doses of any of the agents used in these studies might increase the peripheral deposition of circulating immune complexes. Since patients with ITP frequently have systemic autoimmune disease or circulating immune complexes, the chronic use of Fc receptor blocking agents could adversely affect the course of their disease. An analogous blockade of $\mathrm{Fc}$ receptor function perhaps due to high endogenous IgG levels (36) may account, in part, for the defects in Fc receptor function noted in some patients with immune complex disorders (37).

Clinically, IGIV often benefits patients with autoimmune blood disorders, but because of the very large quantities required it is difficult and expensive to maintain chronic suppression of immune destruction, especially in adults, using this agent. Therefore, the recent report of Clarkson et al. (10) demonstrating that a monoclonal antibody directed against the low avidity Fc receptor present on human neutrophils and macrophages can correct thrombocytopenia in patients with ITP is of great interest. In view of our results, it will be of interest to see whether reductions in complement levels and/or defects in MPS function comparable to those reported in this manuscript also will be observed following infusion of anti Fc receptor antibody in a clinical setting. If so, attempts to minimize these changes may be warranted, since defects in MPS function may impair the host response to some types of stress (34).

\section{Acknowledgments}

The authors wish to thank Bernice Riley and Thomas Matthews for their assistance and advice in completing these studies.

\section{References}

1. Imbach, P., S. Barandum, V. d'Apuzzo, C. Baumgartner, A. Hirt, A. Morell, E. Rossi, M. Schoni, M. Vest, and H. P. Wagner. 1981. Highdose intravenous gamma-globulin for idiopathic thrombocytopenic purpura in childhood. Lancet. 1:1228-1230.

2. Bussel, J. B., R. P. Kimberly, and R. D. Inman. 1983. Intravenous gamma-globulin for chronic idiopathic thrombocytopenic purpura. Blood. 62:480-486.

3. Newland, A. C., J. G. Treleaven, R. M. Minchinton, and A. H. Waters. 1983. High-dose intravenous IgG in adults with autoimmune thrombocytopenia. Lancet. 1:84-87.

4. Fehr, J., V. Hofmann, and U. Kappeler. 1982. Transient reversal 
of thrombocytopenia in idiopathic thrombocytopenic purpura by highdose intravenous gamma globulin. N. Engl. J. Med. 306:1254-1258.

5. Bussel, J., P. Lalazari, M. Hilgartner, J. Partin, S. Fikrig, J. O'Malley, and S. Barundum. 1983. Reversal of neutropenia with IGIV in autoimmune neutropenia of infancy. Blood. 62:398-400.

6. Imbach, P., and T. W. Jungi. 1983. Possible mechanisms of intravenous immunoglobulin treatment in childhood idiopathic thrombocytopenic purpura (ITP). Blut. 46:117-124.

7. Unkeless, J. C. 1979. Characterization of a monoclonal antibody directed against mouse macrophage and lymphocyte Fc receptors. $J$. Exp. Med. 150:580-596.

8. Fleit, H. B., S. D. Wright, and J. C. Unkeless. 1982. Human neutrophil Fc-gamma receptor distribution and structure. Proc. Natl. Acad. Sci. USA. 79:3275-3279.

9. Perussia, B., and G. Trinchieri. 1984. Antibody 3G8, specific for the human neutrophil $\mathrm{Fc}$ receptor, reacts with natural killer cells. $J$. Immunol. 132:1410-1415.

10. Clarkson, S., J. Bussel, R. Kimberly, J. Valinsky, I. Unkeless, and $R$. Nachman. 1985. Platelet increase in refractory ITP after infusion of monoclonal anti-Fc receptor antibody. Blood. 66:287a. (Abstr.)

11. Haeffner-Cavaillon, N., K. J. Dorrington, and M. Klein. 1979. Studies on the $\mathrm{Fc}$ gamma receptor of the murine macrophage-like cell line P388D1. II. Binding of human IgG subclass proteins and their proteolytic fragments. J. Immunol. 123:1914-1919.

12. Springer, T., G. Galfre, D. S. Secher, and C. Milstein. 1979. Mac1: a macrophage differentiation antigen identified by monoclonal antibody. Eur. J. Immunol. 9:301-306.

13. Beller, D. I., T. A. Springer, and R. D. Schreiber. 1982. AntiMac-1 selectively inhibits the mouse and human type three complement receptor. J. Exp. Med. 156:1000-1009.

14. Kurlander, R. J., D. M. Ellison, and J. Hall. 1984. The blockade of $\mathrm{Fc}$ receptor-mediated clearance of immune complexes in vivo by a monoclonal antibody $(2.4 \mathrm{G} 2)$ directed against Fc receptors on murine leukocytes. J. Immunol. 133:855-862.

15. Ey, P. L., S. J. Prowse, and C. R. Jenkin. 1978. Isolation of pure IgG1, IgG2a and IgG2b immunoglobulins from mouse serum using protein A sepharose. Immunochemistry. 15:429-436.

16. Lowry, O. H., N. J. Rosebrough, A. Farr, and R. Randall. 1951. Protein measurement with the folin phenol reagent. J. Biol. Chem. 193: 265-275.

17. Dickler, H. B., and H. G. Kunkel. 1972. Interaction of aggregated gamma-globulin with B lymphocytes. J. Exp. Med. 136:191-196.

18. Rittenberg, M. B., and K. L. Pratt. 1969. Anti-trinitrophenyl (TNP) plaque assay. Primary response of Balb/c mice to soluble and particulate immunogen. Proc. Soc. Exp. Biol. Med. 132:575-581.

19. Mannik, M., W. P. Arend, A. P. Hall, and B. Gilliland. 1972. Studies on antigen-antibody complexes. I. Elimination of soluble complexes from rabbit circulation. J. Exp. Med. 133:713-739.

20. Markwell, M. A. K. 1982. A new solid state reagent to iodinate proteins. I. Conditions for the efficient labeling of antiserum. Anal. Biochem. 125:427-432.
21. Elkon, K. B., P. P. Ferjencik, M. J. Walport, A. M. Peters, S. M. Lewis, and G. R. V. Hughes. 1982. Evaluation of heat-damaged and IgG-coated red cells for testing reticuloendothelial function. J. Immunol. Methods. 55:253.

22. Mayer, M. M. 1961. In Experimental Immunochemistry. 2nd ed. E. Kabat and M. M. Mayer, editors. Charles C. Thomas Publisher, Springfield, IL. 133-240.

23. Pepys, M. B. 1972. Role of complement in induction of the allergic response. Nature (New Biol.). 237:157-159.

24. Friedrich, E. A., J. Aulenbacher, J. Schlepper-Schafer, and R. Suss. 1982. Kupffer cells recognize trinitrobenzene-labeled erythrocytes. Immunol. Lett. 4:167-170.

25. Frank, M. M., A. D. Schreiber, J. P. Atkinson, and C. J. Jaffe. 1977. Pathophysiology of immune hemolytic anemia. Ann. Intern. Med. 87:210-222.

26. Lo Buglio, A. F., R. S. Cotran, and J. H. Jandl. 1967. Red cells coated with immunoglobulin G: binding and sphering by mononuclear cells in man. Science (Wash. DC). 158:1582-1585.

27. Kavai, M., M. Sandor, G. Y. Szegedi, G. Fust, and J. Gergely. 1981. Effect of soluble immune complexes on Fc and $\mathrm{C} 3$ receptor-dependent phagocytosis by human monocytes. Immunology. 44:599-606.

28. Petz, L. D., and G. Garratty. 1980. Acquired Immune Hemolytic Anemias. Churchill-Livingston, Inc., New York. 185-230.

29. Hauch, T., and W. F. Rosse. 1977. Platelet bound complement (C3) in immune thrombocytopenia. Blood. 50:1129-1136.

30. Segal, D. M., and E. Hurwitz. 1977. Binding of affinity crosslinked oligomers of $\mathrm{IgG}$ to cells bearing Fc receptors. J. Immunol. 118 : 1338-1347.

31. Kurlander, R. J., and J. Batker. 1982. The binding of human immunoglobulin G1 monomer and small, covalently cross-linked polymers of immunoglobulin G1 to human peripheral blood monocytes and polymorphonuclear leukocytes. J. Clin. Invest. 69:1-8.

32. Kurlander, R. J. 1980. Reversible and irreversible loss of Fc receptor function of human monocytes as a consequence of interaction with immunoglobulin G. J. Clin. Invest. 66:773-781.

33. Ishizaka, K., T. Ishizaka, and D. H. Campbell. 1959. The biologic activity of soluble antigen-antibody complexes. II. Physical properties of soluble complexes having skin irritating activity. J. Exp. Med. 109: 127-143.

34. Saba, T. M., and E. Jaffe. 1980. Plasma fibronectin (opsonic glycoprotein): its synthesis by vascular endothelial cells and role in cardiopulmonary integrity after trauma as related to reticuloendothelial function. Am. J. Med. 68:577-594.

35. Segal, D. M., S. K. Dower, and J. A. Titus. 1983. The role of non-immune IgG in controlling IgG-mediated effector functions. Mol. Immunol. 20:1177-1189.

36. Kelton, J. G., J. Singer, J. Gauldie, P. Horsewood, and P. Dent. 1985. Concentration of $\mathrm{IgG}$ in the serum is a major determinant of $\mathrm{Fc}$ dependent reticuloendothelial function. Blood. 66:490-495.

37. Frank, M. M., T. J. Lawley, M. I. Hamburger, and E. J. Brown. 1983. Immunoglobulin $\mathrm{G} F \mathrm{c}$ receptor-mediated clearance in autoimmune diseases. Ann. Intern. Med. 98:206-218. 